\title{
A FURTHER STUDY OF LEAF DEVELOPMENT
}

\author{
FREDERIC T. LEWIS
}

IN a previous paper (Amer. Nat., 1907, vol. 41, p. 431-441) the writer discussed whether certain forms of adult leaves could be regarded as due to arrested development, so that by comparing the mature leaves of a given plant something of their embryological history could be learned. It was found that where leaflets are formed embryologically from the base toward the apex, as in most pinnate leaves, the terminal leaflet of the mature leaf is often lobed. Where leaflets are formed from the apex toward the base, as in most palmate leaves, the basal leaflets are often lobed. In the rose, in which the leaflets are also formed from the apex toward the base, neither apical nor basal leaflets are lobed, but new leaflets appear near the stipules to which they are often joined. In the previous paper the sumac and honey locust were described as basifugal forms, and the blackberry and rose as basipetal, the latter being of the stipular type. In the following pages it will be shown that the basipetal and basifugal directions of growth may both occur in a single leaf; and that, although one becomes predominant, evidences of the other are apparent. In some cases a single species presents both pinnate and palmate leaves.

The simplest form of compound leaf is three-parted or ternate, and is produced by the lateral lobation of a simple leaf. The stages in this process as seen in the mature leaves of Clematis virginiana are shown in Figs. 1a-1.d. A ternate leaf may be basipetal in character and pass on to digitate forms with four, five, or more leaflets, or it may be basifugal and produce pinnate leaves. The leaf of Clematis, Fig. 1d, exhibits both tendencies. Basipetal growth is manifest in the coarser teeth on the lower margins of the lateral leaflets and in the fact that the part of each lateral leaflet below the midrib is wider than the part above. Basifugal growth is shown in the coarse tooth on either side of the apical leaflet. Although Clematis virginiana stops ordinarily at this 
stage, the "very similar" western Clcmatis ligusticifolia goes further, and, by the deepening of the notches in the terminal leaflet, becomes pinnate with five leaflets. Many other species of Clematis, including some which are commonly cultivated, have pinnate leaves.

In the poison ivy, Rhus toxicodendron, simple leaves are occasionally found, but the typical form is ternate. Many leaves exhibit both basipetal and basifugal features (Fig. 2a), and explain the occurrence of both palmate and pinnate leaves in this species (Figs. $2 \mathrm{~b}$ and 2c).

An interesting comparison mav be made between the leaves of the black raspberry, Rubus occidentalis, and the wild red raspberry, Rubus strigosus. In the former, Figs. $3 \mathrm{a}$ and $3 \mathrm{~b}$, the basipetal tendency predominates, leading to pedate leaves; a basifugal notching oî the terminal leaflet is, however, often observer. In the closely related red raspberry basifugal growth leads to pinnate leaves, Figs. 4a and 4b, but basipetal lobation may be seen in the basal leaflets.

The form of leaf shown in Figs. 1d, 2a, 3a, and 4a is seen also in Fig. 5a from Negundo aceroides. In the pinnate leaves of this species there may be a basal secondary leaflet, as shown in Fig. 5b. Such evidence of basipetal growth in pinnate leaves is often found. It appears in the long leaves of Ailanthus glandulosus (Fig. 6b). In the seedling of this species, ternate leaves with basal notches have been drawn by Jackson, ${ }^{1}$ from whose paper Fig. 6a has been taken. Thus it is evident that the basipetal and basifugal directions of growth are present together in a great variety of leaves.

The relation of the basipetal secondary leaflets to twice pinnate leaves is shown in Figs. 7, 8. and 9. In the elder, Sambucus canadensis, the basifugal development of primary leaflets is shown in Fig. 7a. ${ }^{2}$ The basipetal formation of secondary leaflets appears

${ }^{1}$ Jackson, R. T. Localized stages in development in plants and animals. Mem. Boston Soc. Nat. Hist., 1899, vol. 5, pp. 89-153.

${ }^{2}$ Goebel (Organographie der Pflanzen, Jena, 1900, pt. 2, vol. 2, p. 525) classes Sambucus cbulus with the basipetal leares and Sambucus nigra with the basifugal. He states,- " "Since in nearly related plants the order of development of pinnate leaflets is sometimes basifugal and sometimes basipetal, not much importance can be attached to this distinction." 


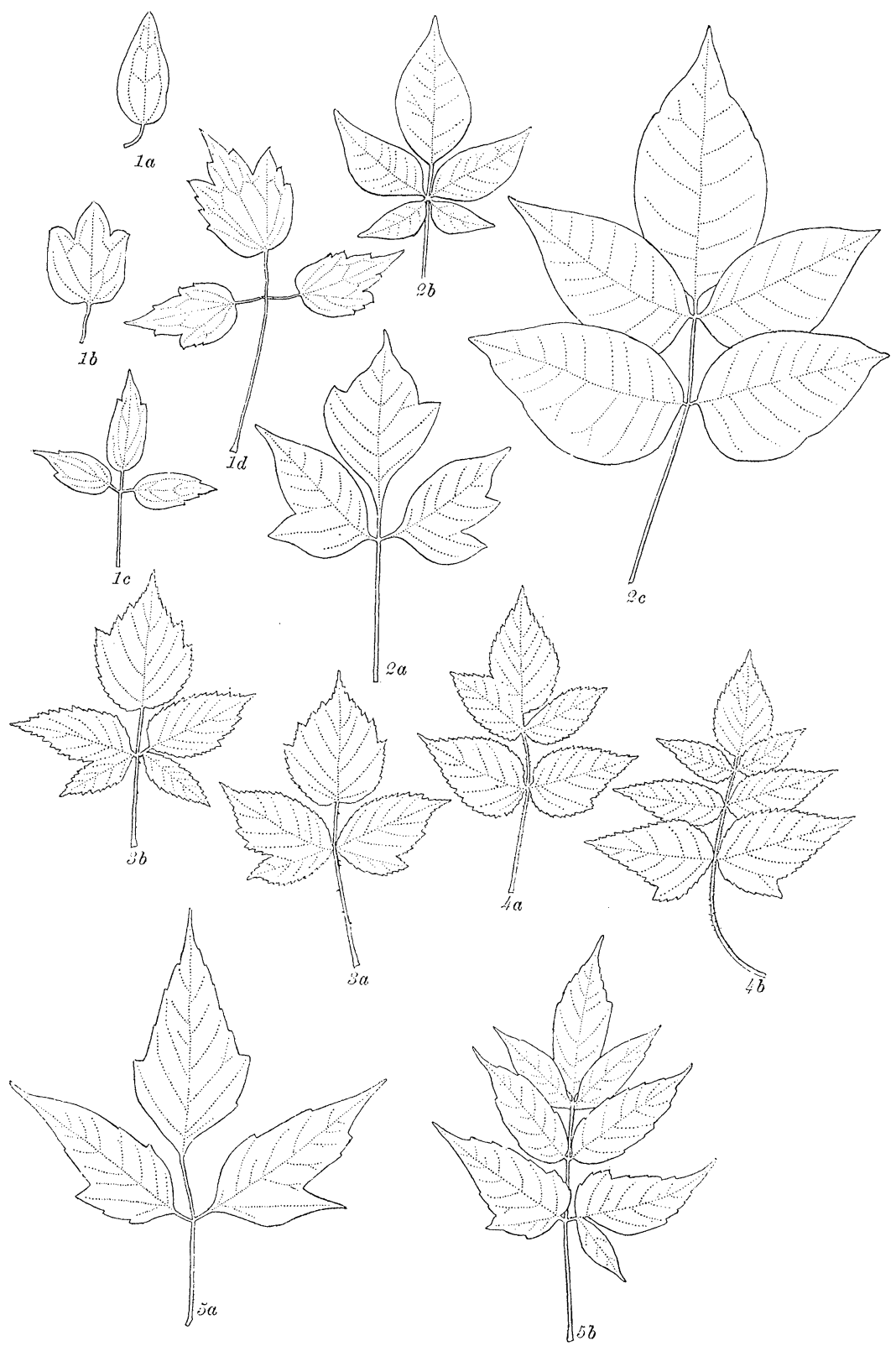

FIGs. 1a-1d, mature leaves of Clematis virginiana L. 2a-2d, Rhus toxicodendron L. 3a-3b, Rubus occidentalis L. 4a-4b, Rubus strigosus Michx. 5a-5b, Negundo aceroides Moench. - $\frac{1}{4}$ natural size, except $1 \mathrm{a}, 1 \mathrm{~b}, 1 \mathrm{c}$, and $2 \mathrm{~b}$ which are $\frac{2}{5}$.

This content downloaded from 080.082.077.083 on January 19, 2018 19:32:57 PM All use subject to University of Chicago Press Terms and Conditions (http://www.journals.uchicago.edu/t-an 
in Fig. 7b. If the process of compounding proceeds further, a smaller secondary leaffet will be cut off opposite the one on the lower border of the primary leaflet (Fig. 7c). Thus the basal primary leaflet becomes pinnate and develops further in the basifugal manner. This order of leaflet formation is seen not only in the elder, but in Aralia nudicaulis (Figs. 8a-8c) and in Cicuta maculata (Figs. 9a-9b). It is of widespread occurrence.

An unusual exception to the basal formation of secondary leaflets is seen in many leaves of Bidens frondosa (Fig. 10). In this species the secondary leaflets are usually on the upper margin of the basal leaflets. They may become matched by leaflets on the lower margin, and sometimes the leaflet on the lower side is formed first. Frequently in Sambucus canadensis the secondary leaflets first appear on the distal sides of the basal leaflets, as in Bidens, but usually they develop on the basal side, both in Sambucus and in most of the species examined.

The development of the pinnate leaves of the rose, as described in the previous paper, is so different from that of other pinnate leaves as to require further study. Eichler ${ }^{1}$ has classed with the rose, as basipetal in development, the leaves of Sanguisorba offcinalis, Poterium sanguisorba, Potentilla anserina, and " probably all potentillas with compound and divided leaves." The basipetal nature of the palmate leaves of Potentilla canadensis is obvious. In "Gray's Manual" they are described as "ternate but apparently quinate by the parting of the lateral leaflets." Frequently they develop seven leaflets without lobation of the central leaflet. In Potentilla fruticosa, however, the central leaflet shows various degrees of indentation, and if one may judge from mature leaves, basifugal growth occurs. The entire leaf is pinnate. Potentilla anserina also shows lobed terminal leaflets. ${ }^{2}$ It is possible in these forms that the proximal leaves are arded basipetally but they are not connected with the stipules, and lobed proximal leaflets were not observed in the plants examined.

The same is true of agrimony leaves. Basal lobation and fusion with stipules were not observed. Terminal lobation (Fig. 11) was shown in two leaves among four hundred and fifty.

${ }^{1}$ Eichler, A. W. Zur Entwickelungsgeschichte des Blattes. Marburg, 1861, $60 \mathrm{pp}$.

${ }^{2}$ Goebel agrees with Eichler in considering Potentilla anserina as basipetal. 


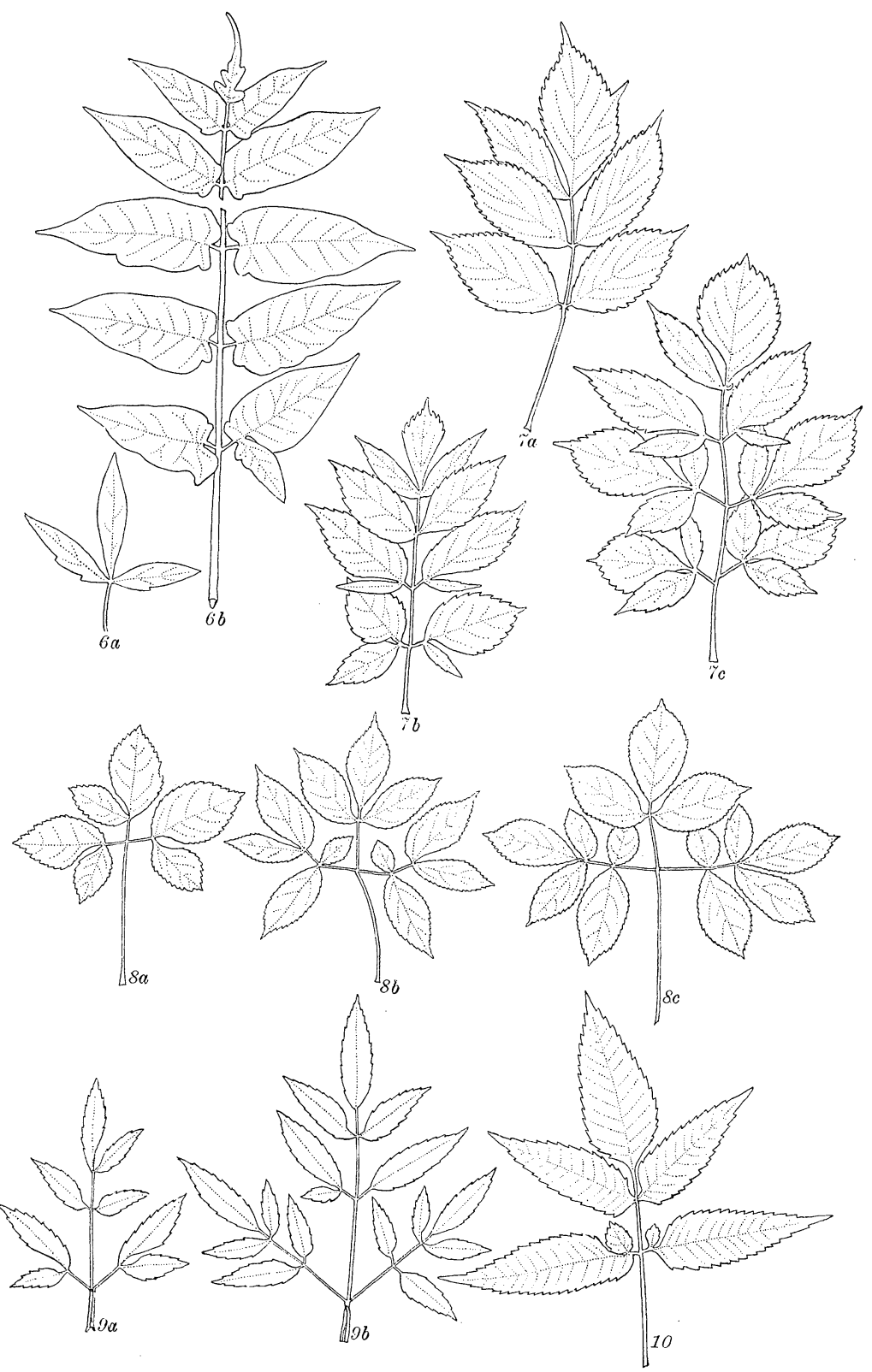

Figs. 6a-6b, Ailanthus glandulosus Desf.; 6a, from a seedling, after Jackson; 6b, the distal and proximal parts of a mature leaf having 13 pairs of leaflets. $7 \mathrm{a}-$ 7c, Sambucus canadensis L. Sa-8c, Aralia nudicaulis L. 9a-9b, Cicuta maculata L. 10, Bidens frondosa L. $-6 \mathrm{a}, \times \frac{5}{6} ; 6 \mathrm{~b}, \times \frac{1}{6} ; 9 \mathrm{a}$ and $9 \mathrm{~b}, \times \frac{1}{3}$; the others, $\times 1$.

This content downloaded from 080.082.077.083 on January 19, 2018 19:32:57 PM All use subject to University of Chicago Press Terms and Conditions (http://www.journals.uchicago.edu/t-an 
Twenty-seven hundred leaves of Rosa lucida yielded none with a lobed terminal leaflet, but basifugal growth was suggested by the two leaves figured as $12 \mathrm{a}$ and $12 \mathrm{~b}$. Several leaves with secondary leaflets attached to the distal pair of primary leaflets were observed (Fig. 12c). In Sambucus, Aralia, and Cicuta, the oldest leaflets are the ones which give rise to secondary leaflets, and they are consequently found toward the base of the leaf. Their distal position in the rose may be correlated with basipetal development. In the celandine, however, in which growth seems clearly basifugal, the distal leaflets produce secondary leaflets as in the rose (Figs. $13 \mathrm{a}$ and $13 \mathrm{~b})$.

Among the twenty-seven hundred rose leaves there were none with the proximal leaflets lobed. One pedate leaf was found (Fig. 12d) together with several forms like that in Fig. 12e. These suggest that leaflets cut off from the basal pair may be carried down the petiole as should occur in a truly basipetal pinnate leaf. However, lobation of the proximal leaflets of a ternate leaf leading to the production of a pinnate leaf has never been found by the writer, and the rose leaves in Figs. 12d and 12e may be explained by the close approximation of the two basal pairs of leaflets.

In the previous paper it was suggested that the first notches in the embryonic rose leaf divided the blade from the stipules, and that the leaflets arose in connection with the latter. The mature apple leaf drawn in Fig. 14a indicates that a notch dividing the blade from the stipule developed on one side only. In small apple leaves the stipules are adherent to the petiole much as in the rose; in larger leaves they are cut off as filiform appendages attached by one end. They may still derelop into leaflets as shown in Fig. 14b. In Sanguisorba and Poterium, which sometimes show a lobed terminal leaftet, there is evidence of stipular basipetal growth. Thus in Poterim canadense a single leaflet or a pair of leaflets may be found close to the stipules and separated by a long stretch of petiole from the more distal leatets. Sometimes the stipules are scarcely to be distinguished from leaflets, to which they are probably giving rise. Such a leaf is figured by Cushman (Amer. Nat., 1903, rol. 37, p. 354) who states that the lowest pair of leaflets has "almost the character of stipules."

In Siun cicutaefolium, which has basifugal pinnate leaves, the 

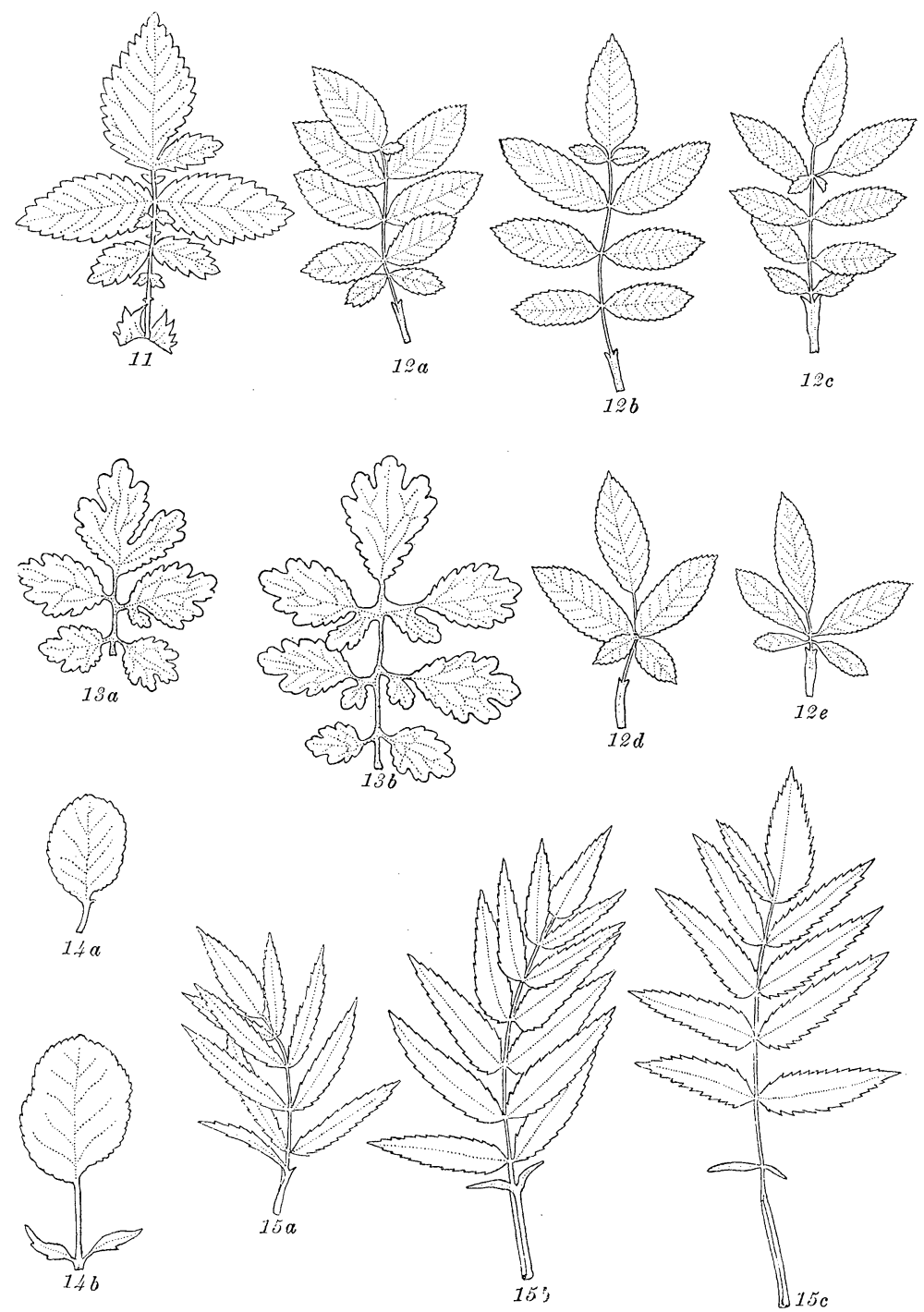

Figs. 11, Agrimonia eupatoria L. 12a-12e, Rosa lucida Ehrh. 13a-13b, Chelidonium majus L. 14a-14b, Pyrus malus L. 15a-15c, Sium cicutaefolium Gmelin.-12e, natural size; $12 \mathrm{c}, 14 \mathrm{a}$. and $14 \mathrm{~b}, \times \frac{1}{2} ; 12 \mathrm{~d}, 15 \mathrm{a}, 15 \mathrm{~b}$, and $15 \mathrm{c}$, $\times \frac{1}{3}$; the others, $\times \frac{1}{4}$.

This content downloaded from 080.082.077.083 on January 19, 2018 19:32:57 PM All use subject to University of Chicago Press Terms and Conditions (http://www.journals.uchicago.edu/t-an 
basal leaflets are often joined to the thin sheath-like stipules. In fact the relation of the leaflets to the stipules is strikingly like that in the rose, as shown in Figs. 15a-15c. In the first there is a well developed leaflet proceeding from the stipule on one side, and there is no corresponding opposite leaflet. In the second the stipules are prolonged into small green leaf-like appendages, and in the third the small pair of leaflets above and separate from the stipules suggests a stipular origin. If this is true, leaflets in sium are added from both ends, and the basal pairs of leaflets are not always homologous as stated by Shull. ${ }^{1}$

Shull's study of Sium supplies an admirably complete record of the leaf-forms presented by a single species. They are, however, considered from the biometric rather than the embryological point of view. Thus the early leaves are divided arbitrarily into six groups or categories. One of these contains the ternate leaves with basally lobed lateral leaflets and three lobed terminal leaflets, - that is, leaves like those of the poison ivy (Fig. 2a) and Negundo (Fig. 5a). This fundamental class which exhibits symmetrically the basipetal and basifugal directions of growth, is described as simply a special case of variously notched three-parted leaves "which was separated from the others only because it could be so definitely characterized." Although shull includes only $20 \%$ of the first leaves of Sium in this category, a large proportion of the forms placed in the remaining five groups are but variations of this type,-- the terminal lobes may be suppressed on one or both sides, the basal lobes may be secondarily notched, etc. The study of Sium shows that the leaves at first exhibit both basipetal and basifugal tendencies and that the latter becomes predominant.

\section{Summary.}

The leaves of very diverse species show a common method of leaf development in which the basipetal and basifugal directions of growth are combined. This is shown by the widespread occurrence of the ternate leaf with the three lobed apical leaflet and

${ }^{1}$ Shull, G. H. Stages in the development of Sium cicutaefotium. Carnegie Inst. of Washington, Publ. No. 30, 1005. 28 pp. 
basally lobed proximal leaflets. This form appears with more or less distinctness in Clematis virginiana, Rhus toxicodendron, Rubus occidentalis, Rubus strigosus, Negundo aceroides, Ailanthus glandulosus, and Sium cicutaefolium. By the predominance of the basipetal or the basifugal element, palmate or pinnate leaves are produced respectively. Twice pinnate leaves develop along the same plan; in becoming twice pinnate a basipetal secondary leaflet becomes matched by a smaller leaflet on the distal border and further development of secondary leaflets in basifugal. This is shown in Sambucus, Aralia, and Cicuta, and the exceptional nature of Bidens is recorded.

The manner of leaf development in the rose requires further study. The formation of leaflets in connection with stipules occurs in Poterium, Sium, and the rose, but in Sium and to a less extent in Poterium they form also from the terminal leaflet. Lobed leaflets in the rose were not found.

Jackson's studies have shown that some Cretaceous leaves are like the simpler stages in the corresponding existing species, notably in the tulip trees. Shull concludes, however, that "no satisfactory inferences can be drawn from ontogenetic leaf-characters regarding the phylogenetic history of the species." $\mathrm{He}$ states that there is need of physiological interpretation, and further biometric studies of leaves are being made. In connection with paleontological and biometric studies it is important that the embryology of leaves should be known, not by inference from mature leaves but by reconstructions of the embryonic stages.

The preceding descriptions of adult leaves show that there is a determinate evolution of leaf forms, whereby diverse species tend to produce similar shapes. Plants with simple leaves constantly show tendencies toward compounding. The "obscurely lobed" leaves of Malva rotundifolia are occasionally deeply divided, and the notches on the red maple leaf may become clefts extending to the petiole. The persistent production of the similar forms of compound leaves which have been described is evidence in favor of determinate or orthogenetic evolution.

Cambridge, Mass. 